National Water-Quality Assessment Program

\title{
Urban Development Results in Stressors That Degrade Stream Ecosystems
}

In 2003, eighty-three percent of Americans lived in metropolitan areas, and considerable population increases are predicted within the next 50 years. Nowhere are the environmental changes associated with urban development more evident than in urban streams. Contaminants, habitat destruction, and increasing streamflow flashiness resulting from urban development have been associated with the disruption of biological communities, particularly the loss of sensitive aquatic biota. Every stream is connected downstream to other water bodies, and inputs of contaminants and (or) sediments to streams can cause degradation downstream with adverse effects on biological communities and on economically valuable resources, such as fisheries and tourism. Understanding how algal, invertebrate, and fish communities respond to physical and chemical stressors associated with urban development can provide important clues on how multiple stressors may be managed to protect stream health as a watershed becomes increasingly urbanized.

This fact sheet highlights selected findings of a comprehensive assessment by the National Water-Quality Assessment Program of the U.S. Geological Survey (USGS) of the effects of urban development on stream ecosystems in nine metropolitan study areas (fig. 1).

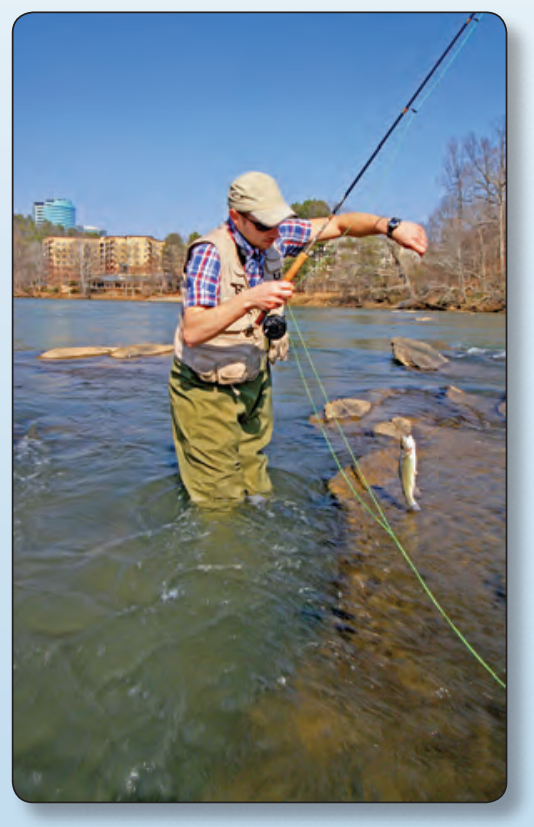

\section{Urban Development Creates Multiple Stressors That Can Degrade Stream Health by Changing Stream Hydrology, Habitat, and Chemistry}

Analyses of how changes in stream hydrology, habitat, and chemistry relate to the species composition of biological communities indicate that no single environmental factor was universally important across all the study areas in explaining the effects of urban development on stream ecosystems. Even within a single study area, the three biological communities that were surveyed—algal, invertebrate, and fish—had different responses to urban development and changing environmental factors. The algal, invertebrate, and fish communities have different life cycles and requirements for food, shelter, and reproduction; consequently, their responses typically vary with stressors that arise from urban-related changes in physical and chemical factors. Different responses among the three communities, however, can provide important clues about the types of stressors that occur with urban development, which then can be linked to management actions that may be appropriate for improving stream conditions.
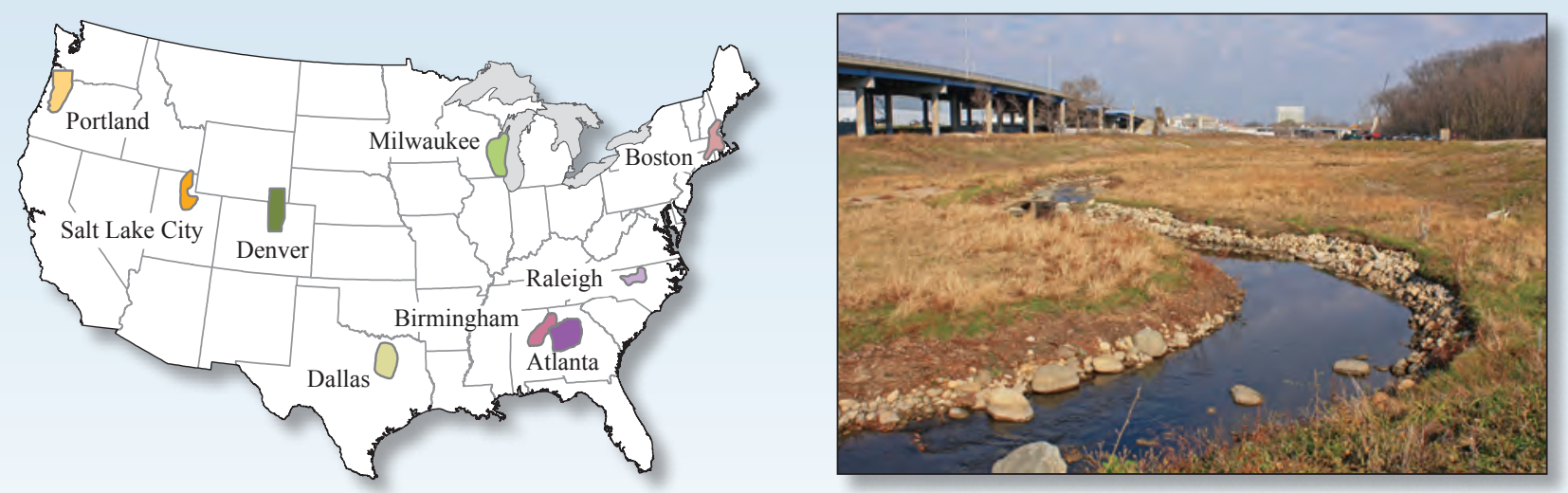

Figure 1. Streams from nine metropolitan areas across the Nation were sampled to assess the effects of urban development on stream ecosystems. Understanding how stream ecosystems change as levels of urban development increase in watersheds can assist in the development of management actions to protect and rehabilitate urban stream ecosystems. The photograph shows a stream in Milwaukee, Wisconsin, that was lined with concrete, but has been reconstructed to replicate a more natural channel. 


\section{Hydrology—Urban Development Leads to Increased Variability in Streamflow}

Urban development typically increases the amount of water entering a stream after a storm and decreases the time that it takes for the water to travel over altered land surfaces before entering the stream. Efforts to reduce flooding by draining water quickly from roads and parking lots can result in increased amounts of water reaching a stream within a short period of time, which can lead to stream flashiness and altered stream channels (fig. 2). Erosion caused by increased streamflow can also degrade the spawning and feeding habitat for fish and reduce the living space for invertebrates. Additionally, rapid runoff reduces the amount of water available to infiltrate the soil and recharge the aquifers, which often results in lower sustained streamflows, especially during the summer.

\section{Habitat-Urban Development Can Alter Stream Channels}

Stream habitats can be severely degraded where urban development occurs along the streambanks, such as where a stream has been straightened by channelization or where manmade structures have replaced natural riparian vegetation. Additionally, urban development that occurs throughout a watershed (but not necessarily directly along the streambank) can result in degraded habitat within a stream channel through flow alteration and sediment erosion. Urban development often results in deeper stream channels or an increase in the stream-channel cross-sectional area. The magnitude of these effects depends on natural environmental factors, such as the geology and soils that can influence the geomorphic characteristics of a stream and its watershed.

\section{Chemistry-Concentrations of Contaminants in Water Increase With Urban Development}

Concentrations of contaminants, including nitrogen, chloride, insecticides, and polycyclic aromatic hydrocarbons (PAHs), increased with urban development, although few measurements exceeded any human or aquatic-life benchmarks. The total concentration of insecticides increased with urban development in seven of the nine study areas. The numbers of individual insecticides detected and the relation between total concentrations of these compounds and the amount of urban development varied across the study areas and appeared to coincide with regional pesticide-use patterns. For instance, higher concentrations of the insecticides chlorpyrifos and chlordane were detected in urban streams in the Atlanta, Dallas, and Raleigh study areas because of the historical use of these compounds for termite control in these areas. These results underscore the importance that regional differences need to be taken into account when comparing the influence of urban development on aquatic biota in different areas.

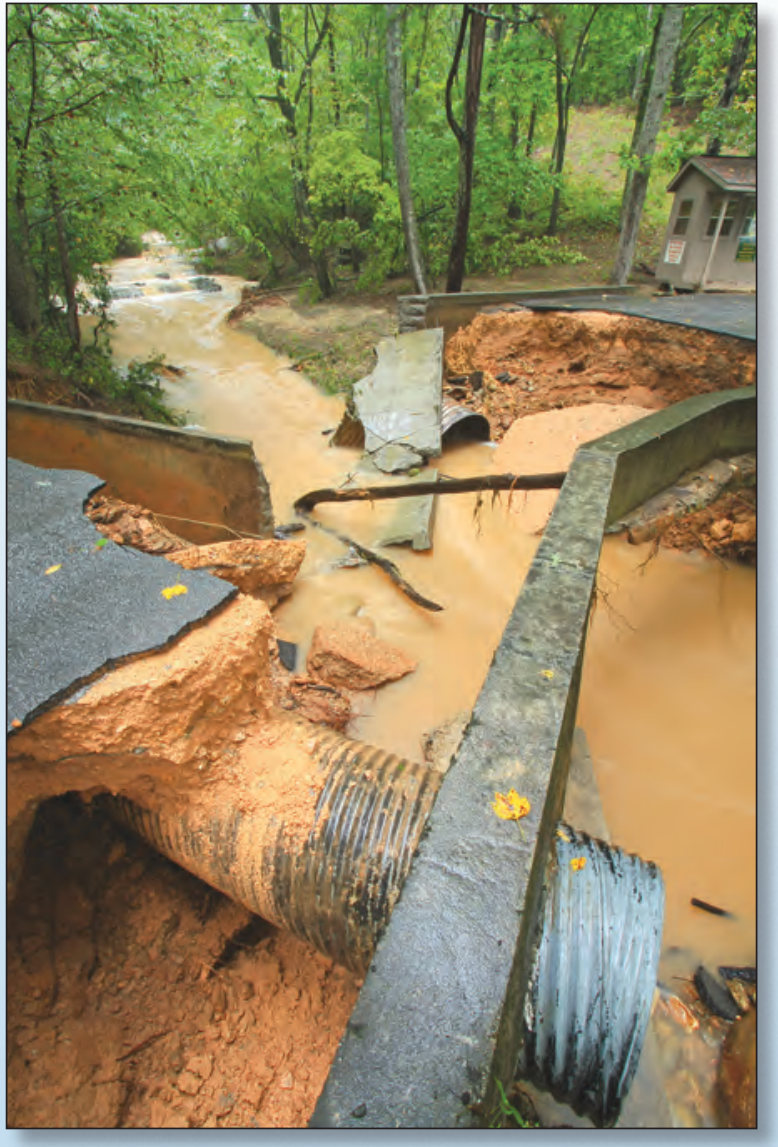

Figure 2. Increases in streamflow volume and frequency can lead to flooding and damage to roads and bridges. These flooding events also erode the streambank, sending sediment downstream. This road crossing was washed out during a flood near Atlanta, Georgia, in 2009.

\section{Aquatic Biota-Loss of Sensitive Species Was the Most Consistent Biological Response to Urban Development}

Urban development generally results in a shift in the species composition of the algal, invertebrate, and fish communities. The most consistent change in any of the biological communities, however, was the loss of sensitive invertebrate species and a shift to a community with a higher percentage of species more tolerant to physical and chemical stressors. A loss in the numbers (richness) of sensitive species, which is related to a decrease in Ephemeroptera (mayflies), Plecoptera (stoneflies), and Trichoptera (caddisflies) invertebrate species (EPT), was a common response in all study areas where urban development occurred in forested watersheds. The number of EPT species is a biological condition metric that is used in many biomonitoring programs across the country because it is sensitive to environmental degradation. A reduction of more than 50 percent of EPT species was observed in some study areas as the percentage of urban development increased in the watersheds from low to high levels. 


\section{The Invertebrate Community Begins to Degrade at the Earliest Stages of Urban Development}

The invertebrate communities begin to degrade at the onset of urban development, which indicates that some invertebrate species are highly sensitive to physical and chemical changes associated with urban development (fig. 3). There was no evidence that the biological communities were resistant to even low levels of urban development, based on the observation that sensitive species were being lost over the initial stages of development in relatively undisturbed watersheds. Likewise, over moderate to high levels of urban development, no exhaustion threshold was observed (typically a "flat line" response) that would have indicated the biological communities were degraded so severely that only the most tolerant species remained. The absence of such an exhaustion threshold indicates that stream-restoration efforts could have a positive effect on the biological condition of a stream regardless of the level of urban development in the watershed.

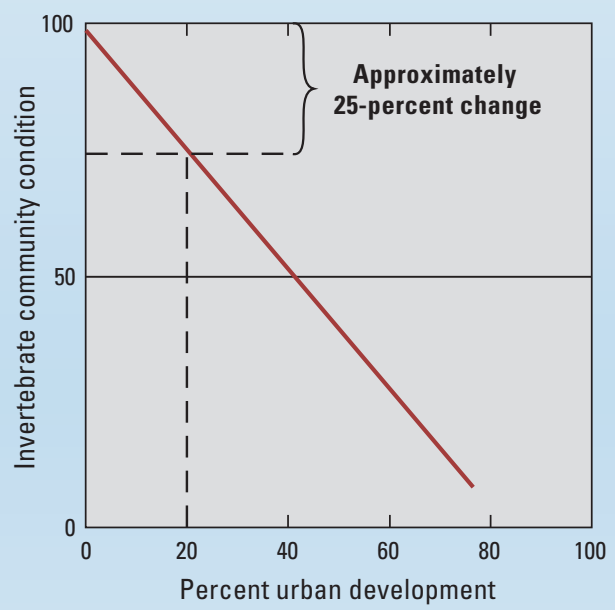

Figure 3. By the time that urban development in the Boston study area was approaching 20 percent, the invertebrate community had declined by approximately 25 percent, based on changes in community condition.

\section{Management Implications}

- Stormwater-management strategies that result in disconnecting impervious cover from the storm-drainage systems may reduce streamflow flashiness, thereby reducing channel erosion and protecting stream habitat.

- Strategies that result in slowing the runoff of precipitation from developed areas to nearby streams can increase infiltration to groundwater, which can help sustain streamflows during the summer and fall and reduce the amounts of contaminants that are transported to streams in stormwater runoff.

- Because the response of algae, invertebrates, and fish to physical and chemical stressors varies, monitoring all three communities provides multiple lines of evidence when assessing the effects of disturbances to aquatic systems.

- Strategies that carefully manage development in undisturbed watersheds are important for minimizing detrimental effects on aquatic biological communities because the degradation of these communities begins at the onset of urban development.

- The lack of an exhaustion threshold in the biotic response indicates that stream-restoration efforts are likely to improve the biological condition of many streams in urban areas.

- The continuous decline in the biological condition of a stream as the amount of urban development increases in a watershed indicates that biological diversity and food-web complexity may be reduced. These types of changes may make the stream, and the ecosystem as a whole, more vulnerable to other changes, such as the introduction of non-native species.

\section{In urban stream ecosystems,}

environmental stressors can have a negative effect on the overall health of the streams. These stressors may include

eroding banks, chemical contaminants, leaking pipes, garbage, impervious surface runoff, invasive and exotic plants and animals, and removal of riparian trees and plants.

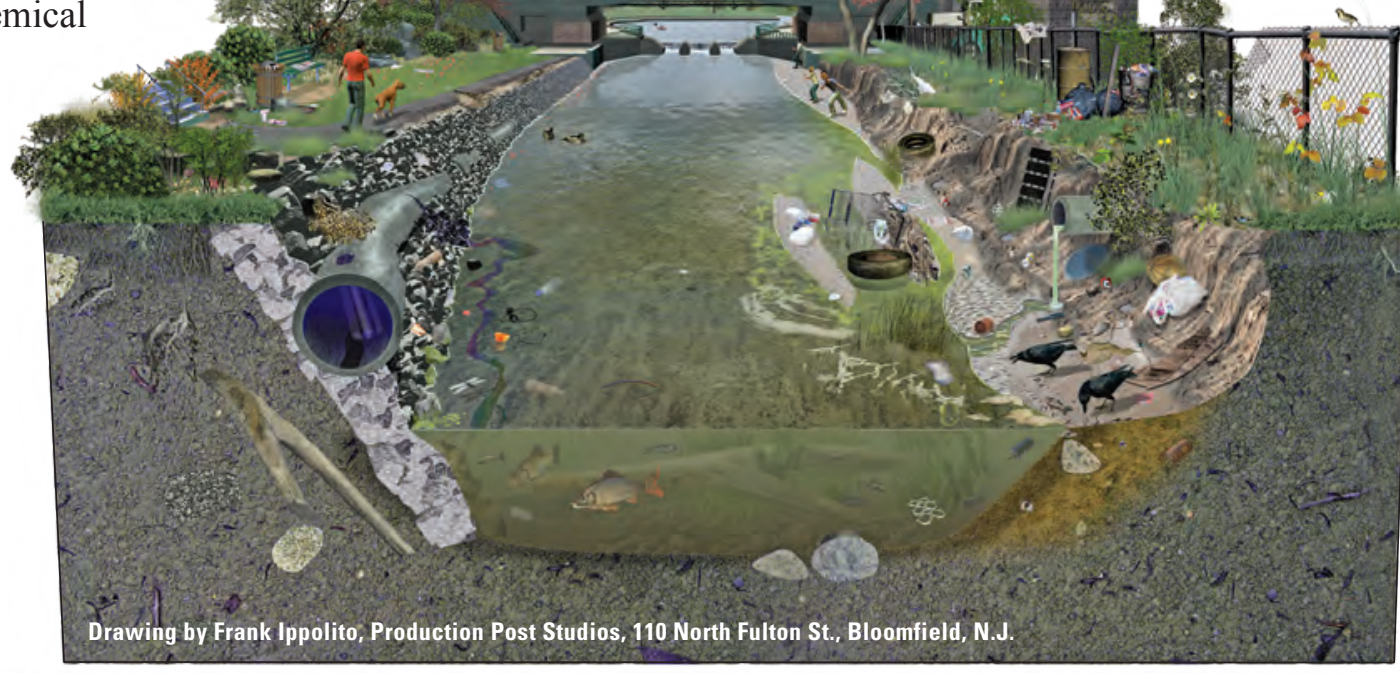




\section{Urban Development Affects Stream Ecosystems Differently Across the Country}

Regional environmental factors, such as climate, geology, topography, and land cover, strongly influence the species composition of the biological communities in streams.

Regardless of the level of urban development in a watershed, the biological communities in sampled streams still had similar community composition characteristics distinct for the region. These regional differences are important to consider when assessing stream health and when designing management strategies for stream remediation.

\section{Regional Differences in the Types of Land Undergoing Urban Development Influenced the Response of Stream Chemistry and Aquatic Biota}

In-stream concentrations of total nitrogen increased with urban development in the Portland, Atlanta, Raleigh, and Boston study areas, which were regions where land cover prior to urban development was primarily forested with total nitrogen concentrations generally at or near background concentrations. In the Denver, Dallas, and Milwaukee study areas, the predominant land cover prior to urban development was agriculture and grassland, which can contribute to elevated total nitrogen. Nitrogen concentrations were relatively high in these streams, even under low levels of urban development. Consequently, relations between urban development and nitrogen concentrations were not as strong in the Denver, Dallas, and Milwaukee study areas as in study areas where urban development occurred on forested land.

The pre-urban land cover was also an important factor in how the biological communities responded to urban development in the Denver, Dallas, and Milwaukee study areas. In these three study areas, the decline in biological communities was consistently less than in the other study areas. The reason for this difference was not because biological communities in these regions are more resilient to stressors from urban development but because the biological communities had already lost sensitive species to stressors from pre-urban agricultural land-use activities. Thus, the biological communities in these three study areas had already been degraded before the onset of urban development (fig. 4).

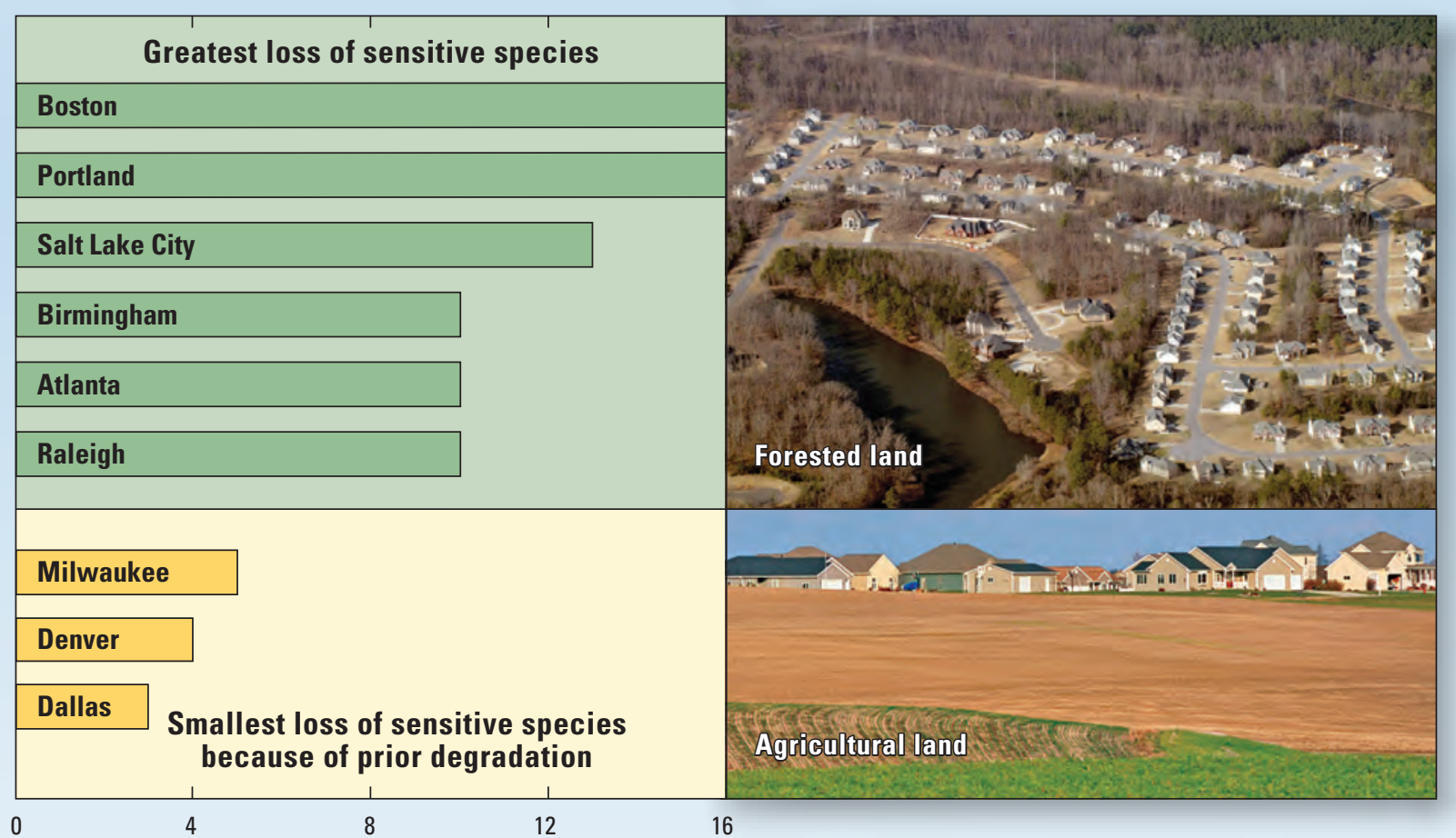

Difference in number of EPT invertebrate species between the least and most developed sites in

Land cover before urban development each study area

Figure 4. The loss of Ephemeroptera, Plecoptera, and Trichoptera (EPT) invertebrate species was greatest when urban development occurred on forested land (green bars). Fewer species were lost in streams of agricultural watersheds (yellow bars) because the biological communities already had endured some degree of degradation associated with agricultural land-use activities, and relatively sensitive EPT species were already absent in streams in these areas. 


\section{How Can This Information Be Used to Manage Urban Stream Ecosystems?}

When evaluating alternative strategies designed to reduce the effects of urban development, managers need methods that account for the dynamic nature of stream ecosystems so that findings can be presented in a way that is scientifically valid and readily understood. Models can play important roles in describing how the physical, chemical, and biological components of these systems interact and for predicting what will happen if changes are made to one or more components.

\section{Using the Biological Condition Gradient to Describe Stream Health}

A model that predicts how urban development affects stream ecosystems is most effective as a management tool if its endpoints and outcomes are stated in terms that are meaningful to scientists, managers, and the public. The Biological Condition Gradient is one modeling approach that can be used to characterize endpoints and outcomes for meeting this goal.

Essentially, this approach provides a standardized framework for evaluating stream health as measured by the biological community (fig. 5). The Biological Condition Gradient is defined by six levels or tiers of stream health, ranging from excellent (natural habitat) to poor (altered habitat), as the biological community degrades from stressors, such as those associated with urban development.
When linked to biological endpoints that are characteristic of streams for a particular region, the tiers are helpful in evaluating management strategies designed to improve stream health. This approach can be used to set realistically attainable goals for stream rehabilitation and to diagnose and correct problems before they become larger.

\section{Innovative Model Predicts How Hydrology, Habitat, and Chemistry Can Affect Stream Health}

In a pilot investigation using data from the Boston study area, an innovative regional model was developed for New England to predict how different combinations of urban-related stressors associated with stream hydrology, habitat, and chemistry affect stream health, as measured by changes in the invertebrate community. The tool can be used to evaluate how changes to one or multiple urban stressors can affect biological endpoints and the likelihood of attaining the desired stream-health goal (fig. 6). The model was structured to predict the probability of attaining six tiers of stream health (fig. 5), which makes it possible for different management scenarios to be evaluated for protecting stream health in urbanizing areas. For example, the model predicted that the likelihood of attaining a healthy stream would be only about 25 percent when the levels of urban development in a watershed exceeded 31 percent. Management actions to improve water quality and reduce stream flashiness are predicted to increase the likelihood of attaining a healthy stream to about 70 percent.

\section{Tiers of biological condition}

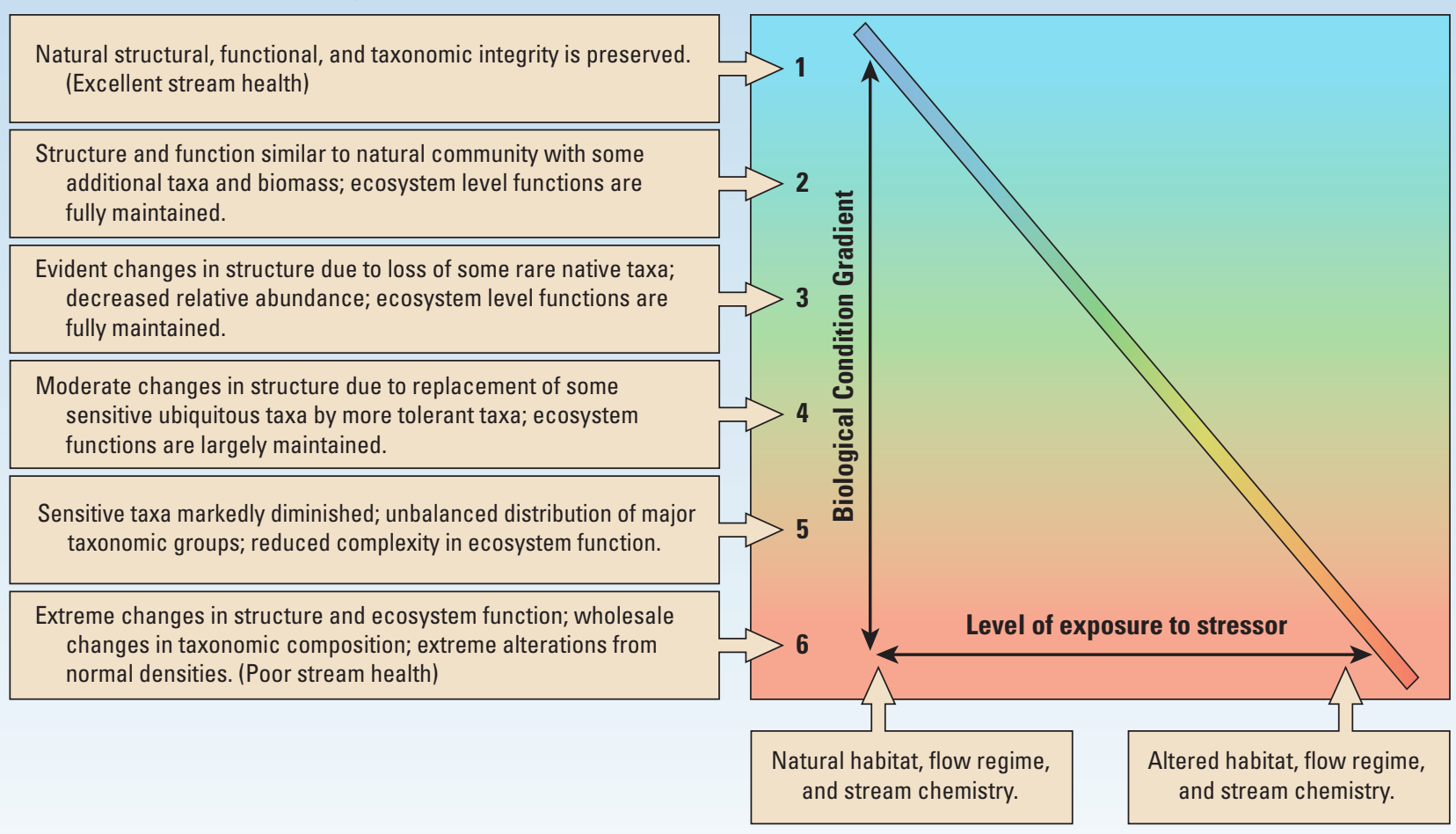

Figure 5. The Biological Condition Gradient can be used to measure and communicate characteristics of stream health. The transition from tiers 1 through 6 ( $y$-axis) indicates a declining biological condition and stream health as the stressor levels increase (x-axis). Modified from Davies and Jackson (2006). 


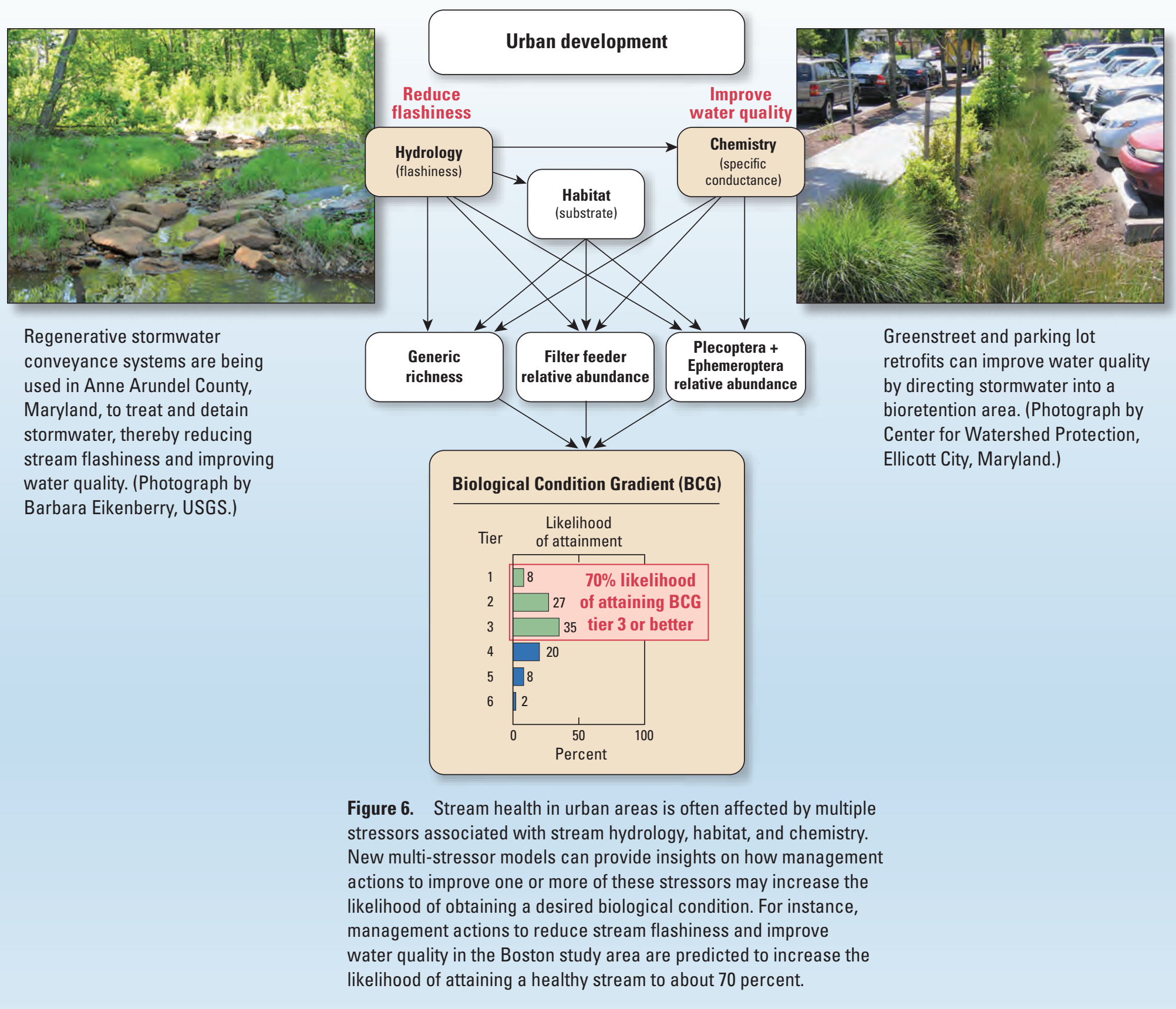

\section{Reference Cited}

Davies, S.P., and Jackson, S.K., 2006, The biological condition gradient: A descriptive model for interpreting change in aquatic ecosystems: Ecological Applications, v. 16, no. 4, p. 1251-1266.

\section{Additional information on the effects of urban development on stream ecosystems is available in the following publication:}

Coles, J.F., and others, 2012, Effects of urban development on stream ecosystems in nine metropolitan study areas across the United States: U.S. Geological Survey Circular 1373, 138 p. (Also available at http://pubs.usgs.gov/circ/1373/.)

Videos, podcasts, articles, and fact sheets describing the USGS assessment of the effects of urban development on stream ecosystems in nine metropolitan areas of the United

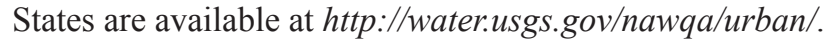
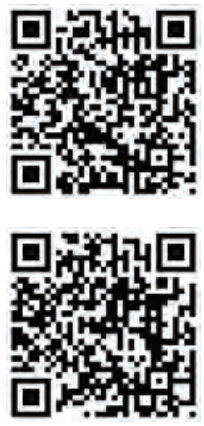

By: Amanda H. Bell, James F. Coles, Gerard McMahon, and Michael D. Woodside

For additional information contact:

Chief, National Water-Quality Assessment Program

U.S. Geological Survey

413 National Center

Reston, VA 20192

Fact sheet photography by Alan M. Cressler, USGS, unless otherwise indicated. 